\title{
AGRICULTURE
}

\section{CHARACTERIZATION OF NEW GEORGIAN MULBERRY SILKWORM BREEDS RELATIVELY RESISTANT TO THE DISEASE «NUCLEAR POLYHEDROSIS»}

\author{
${ }^{1}$ Nargiz Baramidze, doctor of agrarian sciences \\ ${ }^{2}$ Shorena Kharatishvili, doctoral candidate \\ ${ }^{3}$ Lia Mdzeluri, doctoral candidate \\ ${ }^{4}$ Maia Khutsishvili, candidate of agrarian sciences \\ ${ }^{5}$ Zoia Tskaruashvili.
}

\author{
Georgia, Tbilisi, Scientific-Research Center of Agriculture; \\ Georgia, Tbilisi, Agrarian University. \\ ${ }^{1}$ Senior specialist of the Scientific-Research Center of Agriculture; \\ ${ }^{2}$ Consultant at the Scientific-Research Center of Agriculture; \\ ${ }^{3}$ Consultant at the Scientific-Research Center of Agriculture; \\ ${ }^{4}$ Researcher at the Agrarian University; \\ ${ }^{5}$ Researcher at the Agrarian University.
}

DOI: https://doi.org/ 10.31435/rsglobal_ws/30112018/6232

\section{ARTICLE INFO}

Received: 21 September 2018

Accepted: 27 November 2018

Published: 30 November 2018

\section{KEYWORDS}

mulberry silkworm,

selection,

diseases,

silk cocoon,

viability.

\begin{abstract}
The paper considers biotechnological characteristics of new breeds of mulberry silkworm ,V-1" and ,V-2", which are relatively resistant to the worm disease ,nuclear polyhedrosis“. The hybreeds were obtained from mulberry silkworm breeds „Dighmuri“ and „Iveria“. Breed "Iveria” is characterized by short period of feeding; it was created for the west Georgia zone, while the cocoon thread length of the breed "Dighmuri" is $1800-2000$ meter, silk capacity of live cocoon is $25-26 \%$, but these breeds are characterized by relatively low viability $[1,2,3]$. Our research aimed to improve namely this flaw. As a result of complex selection works carried out for the improvement of the above stated viability and other major indices we received new highly productive breeds, which by their indices equal or exceed initial breeds.
\end{abstract}

Citation: Nargiz Baramidze, Shorena Kharatishvili, Lia Mdzeluri, Maia Khutsishvili, Zoia Tskaruashvili. (2018) Characterization of New Georgian Mulberry Silkworm Breeds Relatively Resistant to the Disease «Nuclear Polyhedrosis». World Science. 11(39). doi: 10.31435/rsglobal_ws/30112018/6232

Copyright: (C) 2018 Nargiz Baramidze, Shorena Kharatishvili, Lia Mdzeluri, Maia Khutsishvili, Zoia Tskaruashvili. This is an open-access article distributed under the terms of the Creative Commons Attribution License (CC BY). The use, distribution or reproduction in other forums is permitted, provided the original author(s) or licensor are credited and that the original publication in this journal is cited, in accordance with accepted academic practice. No use, distribution or reproduction is permitted which does not comply with these terms.

Introduction. From the beginning of selction works (1930 y.) more than 50 local selection breeds of mulberry silkworm were obtained. Selected breeds obtained in the first period of works were characterized by short thread length and thinness (800-900 meter, metric number 2000-2200). Because of it, to receive complex silk thread (№429) it was sufficient to wind only 6-7 cocoons jointly, and correspondingly its cocoon thread length, thinness and other indices were rather low. In the following years, biotechnological characteristics of selective breeds were improved and the 
cocoon thread length of the breed "Dighmuri" that was selected in 1985-1989 years reached 1800200 meter, but this breed is characterized by low viability. Because of it, selection was continued for heighten worm viability and its resistance to diseases.

Material and methodology. As starting material we gave preference to local origin breeds (Dighmuri and Iveria) [4,5]. For the study and evaluation of initial breeds and starting populations obtained from those breeds we used a method of preliminary prognosis -by determination of form elements in hemolymph [6,7]. In some cases a method of injection of blood was also used.

To improve viability and to elevate resistance of a disease "nuclear polyhedrosis" in silkworm, we used method of artificial infestation (induction) of mulberry sulkworm. Besides, method of feeding on the provocative background (high temperature, $28-32^{\circ} \mathrm{C}$, humidity more than $90 \%$, rough feed) was also used.

To achieve $100 \%$ infestation of mulberry silkworm by polyhedrosis is factually impossible, only relatively weak worms are infected. This is why hemolymph was collected from diseased worms, as much as possible. Purification of polyhedrons was made by centrifugation at $3000 \mathrm{rev} . / \mathrm{min}$, at $4{ }^{\circ} \mathrm{C}$, in 60, 40 and 29 saccharose linear gradient.

Polyhedrons were counted in Goriaev's chamber and various titers of polyhedron suspensions were prepared: $500 \mathrm{~mm}^{3}, 1000 \mathrm{~mm}^{3}, 5000 \mathrm{~mm}^{3}, 10000 \mathrm{~mm}^{3}, 50000 \mathrm{~mm}^{3}$, which were used for artificial infestation of silkworms.

When the $4^{\text {th }}$ skin was changed, silkworm was counted in 100-100 pcs in 7 variants and 5 variants were given leaf that was sprayed with polyhedron suspensions; the $6^{\text {th }}$ variant was used as a dry control and the $7^{\text {th }}$ variant - as a wet control.

Polyhedron suspensions were tested by carrying out annual reiterated feeding, till the concentration was established, at which a worm would be infested to the level, when it would be able to undergo metamorphosis into a moth and to lay grain.

Results. Mulberry silkworm disease "polyhedrosis" was observed in the $5^{\text {th }}$ instar, at 6-7 day, before cocoon spinning.

Table 1. Number of silkworm infected by polyhedron suspension.

\begin{tabular}{|c|c|c|c|c|c|c|c|c|c|c|c|c|c|c|}
\hline \multicolumn{15}{|c|}{ Variant } \\
\hline $\begin{array}{l}V \text { instar } \\
\text { day }\end{array}$ & \multicolumn{2}{|c|}{$500 \mathrm{~mm}^{3}$} & 100 & $\mathrm{~mm}^{3}$ & \multicolumn{2}{|c|}{$\begin{array}{c}50000 \\
\mathrm{~mm}^{3}\end{array}$} & \multicolumn{2}{|c|}{$\begin{array}{c}10000 \\
\mathrm{~mm}^{3}\end{array}$} & \multicolumn{2}{|c|}{$\begin{array}{c}50000 \\
\mathrm{~mm}^{3}\end{array}$} & \multicolumn{2}{|c|}{$\begin{array}{c}\text { Dry } \\
\text { control }\end{array}$} & \multicolumn{2}{|c|}{$\begin{array}{c}\text { Wet } \\
\text { control }\end{array}$} \\
\hline 1 & \multicolumn{2}{|l|}{-} & \multicolumn{2}{|l|}{-} & \multicolumn{2}{|c|}{-} & \multicolumn{2}{|l|}{-} & \multicolumn{2}{|c|}{-} & \multicolumn{2}{|c|}{-} & \multicolumn{2}{|c|}{-} \\
\hline 2 & \multicolumn{2}{|l|}{1} & \multirow{2}{*}{\multicolumn{2}{|c|}{$\frac{1}{1}$}} & \multirow{2}{*}{\multicolumn{2}{|c|}{$-\overline{1}$}} & \multirow{2}{*}{\multicolumn{2}{|c|}{$\frac{1}{3}$}} & \multicolumn{2}{|l|}{2} & \multicolumn{2}{|l|}{ - } & \multicolumn{2}{|l|}{1} \\
\hline 3 & \multicolumn{2}{|l|}{1} & & & & & & & 3 & & 2 & & 2 & \\
\hline 4 & 1 & & \multicolumn{2}{|l|}{1} & \multicolumn{2}{|l|}{1} & \multicolumn{2}{|l|}{-} & \multicolumn{2}{|l|}{3} & \multicolumn{2}{|l|}{1} & \multicolumn{2}{|l|}{2} \\
\hline 5 & \multicolumn{2}{|l|}{-} & \multicolumn{2}{|l|}{-} & \multicolumn{2}{|l|}{1} & \multicolumn{2}{|l|}{2} & \multicolumn{2}{|l|}{5} & \multicolumn{2}{|l|}{2} & \multicolumn{2}{|l|}{2} \\
\hline 6 & \multicolumn{2}{|l|}{1} & 2 & & 3 & & 3 & & 7 & & - & & 2 & \\
\hline 7 & 1 & & 2 & & 3 & & 3 & & 7 & & - & & 4 & \\
\hline total & $q-t y$ & $\%$ & q-ty & $\%$ & q-ty & $\%$ & q-ty & $\%$ & q-ty & $\%$ & q-ty & $\%$ & q-ty & $\%$ \\
\hline & 5 & 5 & 7 & 7 & 9 & 9 & 12 & 12 & 27 & 27 & 5 & 5 & 13 & 13 \\
\hline
\end{tabular}

The first table offers quantity of individuals, which died as a result of infestation by various concentration polyhedron suspensions, according to days. 78 worms of 700 - died, many died in the process of metamorphosis and relatively healthy moths came out only from 69 cocoons.

According to the above given table, the greatest number of worms died in the version with $50000 \mathrm{~mm}^{3}$ polyhedron suspension, the smaller number died in $500 \mathrm{~mm}^{3}$ variant.

The rescued worms span cocoon and from those cocoons the grain was prepared, which was tested for disease at the next feeding.

The concentrations of polyhedron suspensions when the biggest number of mulberry silkworm died as a result of experiments $\left(50000 \mathrm{~mm}^{3}, 10000 \mathrm{~mm}^{3}, 5000 \mathrm{~mm}^{3}\right.$ and $\left.1000 \mathrm{~mm}^{3}\right)$ were discarded from the test. Finally only one concentration of polyhedron suspension was prepared (500 $\mathrm{mm}^{3}$ ), when small number of worms were infected, and the rescued silkworm reached the moth stage and as a result of pappillonage grain was obtained. Experimental results are given in Table 2. 
Table 2. Number of worms infecstated by polyhedral suspension.

\begin{tabular}{|c|c|c|c|c|c|c|}
\hline Vinstar day & & & \multicolumn{2}{|c|}{ Dry control } & \multicolumn{2}{|c|}{ Wet control } \\
\hline 1 & & & \multicolumn{2}{|c|}{ - } & \multicolumn{2}{|c|}{-} \\
\hline 2 & & & \multicolumn{2}{|c|}{-} & \multicolumn{2}{|c|}{-} \\
\hline 3 & & & \multicolumn{2}{|c|}{ - } & \multicolumn{2}{|c|}{-} \\
\hline 4 & & & \multicolumn{2}{|c|}{ - } & \multicolumn{2}{|c|}{1} \\
\hline 5 & & & \multicolumn{2}{|c|}{-} & \multicolumn{2}{|c|}{1} \\
\hline 6 & & & \multicolumn{2}{|c|}{-} & \multicolumn{2}{|c|}{1} \\
\hline 7 & & & \multirow{2}{*}{\multicolumn{2}{|c|}{$\frac{1}{1}$}} & \multirow{2}{*}{\multicolumn{2}{|c|}{$\frac{1}{1}$}} \\
\hline 8 & & & & & & \\
\hline \multirow[t]{2}{*}{ total } & q-ty & $\%$ & q-ty & $\%$ & q-ty & $\%$ \\
\hline & 4 & 4 & 2 & 2 & 5 & 5 \\
\hline
\end{tabular}

Table 2 offers number of individuals who died at infestation by various concentration polyhedron suspensions and the percentage of lethal end according to days.

According to this table, $4 \%$ of worms was diseased in the first variant, while in the $7^{\text {th }}$ variant (wet control) 5 worms were diseased; in the process of metamorphosis $7 \%$ of worms died while the remaining worms span cocoon and from those cocoons grain was prepared.

From the worms rescued after every experiment the $F_{1 \ldots .} F_{7}$ generation was obtained by the method of sampling, and from that generation by long-term selection and sampling the improved lines were obtained $[8,9,10]$. After each feeding moth microanalysis was carried out and grain laid by diseased moth was discarded.

Simultaneously works were carried out by analytical and synthetic selection methods and sampling from generations [11,12]. Works which aimed to preserve significant technological indices and to improve worm viability in those lines were continued, in particular, by strict rejection and on the basis of non inbred crossing by propagation in generations; sampling of families and individuals with high indices was performed and on its base breed "V-1" was obtained from "Dighmuri" and "V-2" from "Iveria". The obtained breeds are distinguished by high biotechnological indices, especially - by high viability.

The main goal of our research, that is elevation of mulberry silkworm viability in starting breeds from 88,7-91.5 \%- to 95.6-97.3\% was achieved, which is a great achievement in mulberry silkworm selection breeding work.

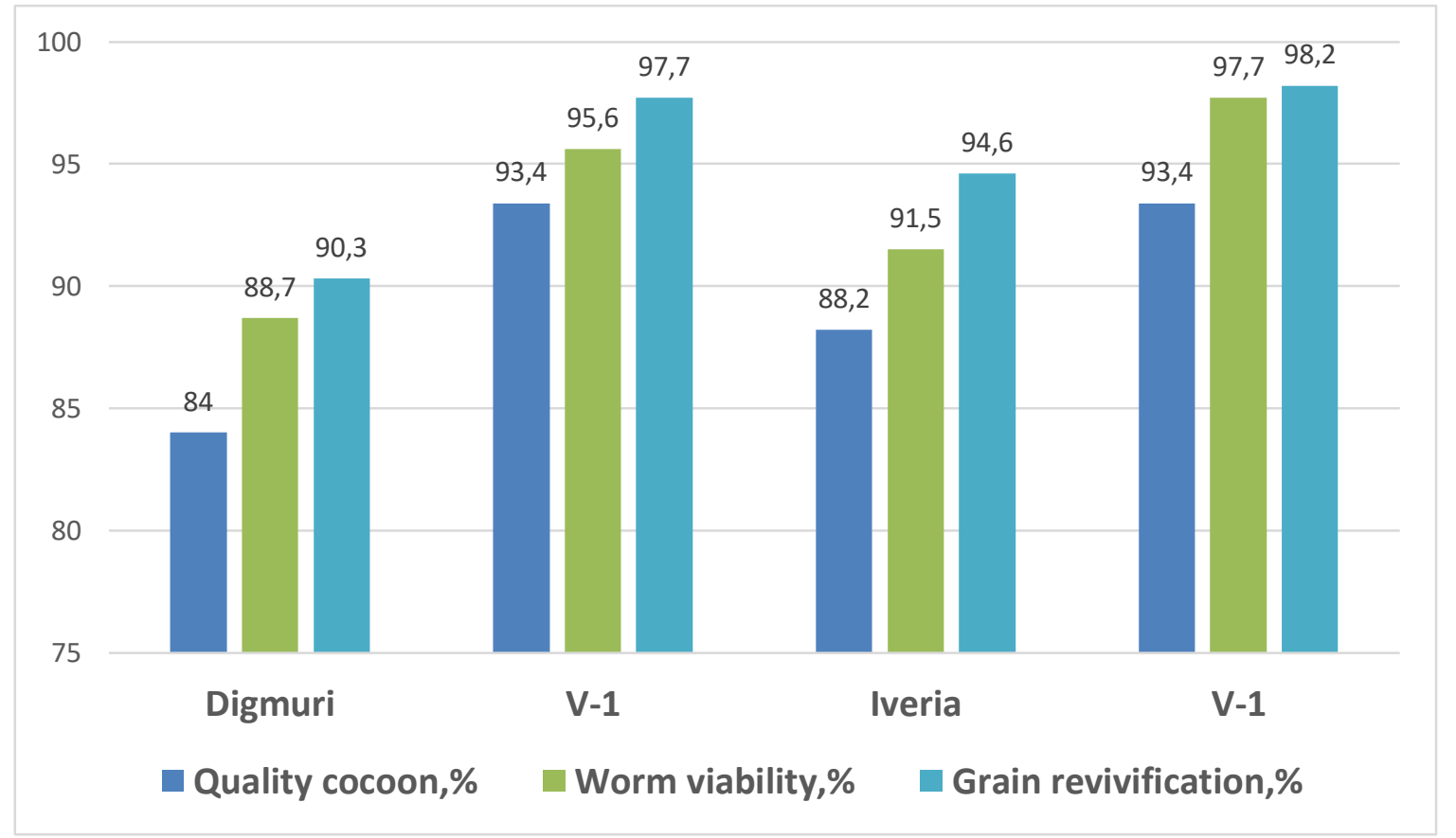

Fig. 1. Diagram 1. Comparison of the main indices of the starting and new breeds of mulberry silkworm 
As to other biotechnological indices, they are significantly improved in the tested breeds and they fully conform to normative demands. Besides, according to the leading signs for sampling (quality cocoon quantity and improvement of viability) these breeds fully justify our preliminary task and it is logical since elevated viability is the prerequisite for obtaining high quality cocoon yield. Irrespective of it, works are continued towards still more improvement of these signs and for stabilization, since both starting and tested breeds possess great potential.

Conclusions.

1. Optimal polyherdal suspension concentration titer was developed $\left(500 \mathrm{~mm}^{3}\right)$.

2. Breeds V-1 and V-2, relatively resistant to the silkworm disease "nuclear polyhedrosis" were obtained by the method of sampling of $F_{1 \ldots .} F_{7}$ generations of healthy worm after artificial infestation of mulberry silkworm, which as a result of analytical and synthetic selection and strict selection/sampling in generations were formulated into the breeds of high biotechnological indices.

3. New breeds are the precious starting materials for selection to receive more highly productive breeds.

\section{REFERENCES}

1. Giorgadze, L.Kobakhidze, E.Tsotskolauri. Estimation of selection efficiency according to warm viability along the one generation period, Collection of Scientific Works of Georgian Agrarian University "Problems of Agrarian Sciences", v. 33, Tbilisi, 2005, p. 92-94.

2. N.Baramidze, M.Khutsishvili, Z.Tskaruashvili, I.Gujabidze. Comparative study of Georgian breeds of mulberry silkworm according to the main biotechnological characteristics. Annals of Agrarian Science. V. 14 (2016), pp. 56-60.

3. Khursishvili M. Correlative dependence between concentration of total proteins of mulberry silkworm hemolymph and biotechnological characteristics. GAU, Collection of Scientific Works, vol.3 (52)2010, Tbilisi, p. 32-35(in Georgian).

4. Butenko A.G. Refraction of mulberry silkworm hemolymph connected with gender and breed. J. "Silk", \#3. Tashkent, 1995 (In Russ.)

5. Begum A., Basavaraja H., Patil A. et al. Studies on the characteristics of cocoon in different breeds of silkworm, Bombyx mori L. // Sericologia, 2004, 44(4), p.497-512. www.silkwormmori. blogspot.com

6. Grekov D., Kirovska N., Avramova K. Dynamics of the major biological parameters in some lines of the silkworm (Bombyx mori L.) from Japanese type / Proc. of International jubilee scientific conference: Problems of maintenance and utilbzation of mulberry and silkworm genetic resources (2006.Bulgaria). Dobrich: Integral, 2007, p.293-300.www.bacsa-silk.org

7. Kipriotis E., Kousenidis K. Some practical aspects involved to silkworm breeding / Proc. of International jubilee scientific conference: Problems of maintenance and utilization of mulberry and silkworm genetic resources 2006, Bulgaria. Добрич: Интеграл, 2007, p.194-201. www.bacsa-silk.org

8. Lakshmi H., Ramesh-Babu M., Prasad J., Chandrashekharaiah A. Identification of promising cross breed APM1 x APS98 in mulberry silkworm through mani-festation of hybrid vigour // Bull. Ind. Acad. Ser., 2008, 12, p. 1-11. www.bacsa-silk.org.

9. Lazarov Y. Tzenov P., Nacheva Y. Study on the tolerance of silkworm (Bombyx mori L.) hybrids to unfavorable conditions of rearing // Bulgarian J. of Agric. Sci., 2000, 6, N 5, p. 589-592

10. Mano Y., Kumar S., Basavaraja H. et al. A new methods to select promising breeds and combinations // Indian Silk, 1993, 31, p. 53-59. www.silkwormmori. blogspot.com

11. Mubashar Hussain, Shakil Ahmad Khan, Muhammad Aslam. Evaluation of genetic potential of inbred pure lines of silkworm for breeding and cocoon production in Pakistan // African Journal of Food Science, 2010, v. 4(5), pp. 300 -302/May 2010,

12. Nacheva Y., Petkov N. Rates of genetic difference between parent breeds of silkworm moth Bombyx mori L. hybrids for the indexes of intracocoon unevenness and inter cocoon concordance of the silk filament. Bulgarian J.of Agric Sci., 2001,6, № 7,p.107-110. 